\title{
THE DOME OF THE TEMPLE OF DIANA IN BAIAE: GEOMETRY, MECHANICS AND ARCHITECTURE
}

\author{
A. SINOPOLI ${ }^{1}$, D. AITA $^{2}$ \\ ${ }^{1}$ Department of Structural and Geotechnical Engineering \\ Sapienza University, Rome, Italy \\ e-mail: anna.sinopoli@uniroma1.it \\ ${ }^{2}$ Department Architecture and Design \\ University of Genoa, Italy \\ e-mail: danila.aita@edu.unige.it
}

Keywords: Opus caementicium, Domes, Geometry, Building techniques, Structural analysis

\begin{abstract}
The purpose of this paper, which is part of a multi-disciplinary research project started in 2018 [1], is to investigate both the geometry and stability of the dome of the temple of Diana, which partially survived for many centuries. Important observations made by De Angelis d'Ossat [2] and results of the architectonic survey performed by Rakob [3] will be presented and discussed; they introduce the delicate issue concerning the identification of the geometric profile of the dome, on which its structural stability depends. It is the Authors' opinion that ascertaining the geometric profile of a dome is not only a matter of measuring, but also of historical context, geometric knowledge and traditions in construction. Thus, by taking all the above issues into account and making use of data from a recent architectonic survey [1], this paper searches for possible connections with consolidated traditions of the Sassanid architecture imported by the Emperor Alexander Severus, verifies the geometric knowledge presumed to have been acquired by the time of the dome's construction and identifies the most probable theoretical design: the dome's meridian profile is a unique curve - to be precise, a parabola, the best approximation of a catenary. Thus, once the profile of the dome has been identified, structural analysis confirms not only the stability of the dome, but also that the Romans were aware of the dome's behaviour in relation to the construction solutions adopted.
\end{abstract}

\section{INTRODUCTION}

Roman mortar, a refinement of the most ancient building systems, common throughout the Mediterranean basin since at least the $5^{\text {th }}$ century BC, was introduced into Roman building methods from at least the $3^{\text {rd }}$ century BC. It consisted of slaked lime and fillers such as "pozzolana" sand, gravel, and "cocciopesto" (crushed earthenware, tiles, and/or bricks).

It was only in the $1^{\text {st }}$ century $\mathrm{AD}$ that opus caementicium began to be used on a massive scale; at first, only for the interior design of buildings and then, in the $2^{\text {nd }}$ and $3^{\text {rd }}$ centuries AD, for various types of public buildings and territorial urbanization. Certainly, the switch from a radial arrangement of the elements used in the construction of arches and vaults to the horizontal layout typical of the caementa in opus caementicium is in line with the principle of economy and industrialization of the construction process, which determined the building technique 
typical of Roman architecture. The Romans extended experimentation with opus caementicium from the $1^{\text {st }}$ century AD by using it also to build domes.

In this paper the dome of the temple of Diana will be investigated with a double purpose: to ascertain the dome profile adopted by the Romans, and to verify the consequence on the dome's structural stability. In Section 2 geometrical and architectonic features of the dome will be presented. Section 3 is focused on the historical reconstruction of the events that probably induced the Roman emperor Severus to build this temple in Baiae. Section 4 analyses the debated question of the dome profile, by discussing the results of the surveys performed up to now. Section 5 tackles the problem of searching for a possible geometric profile, both theoretical and experimental, by identifying the distributions of deviations of the theoretically presumed profiles of the meridians from the corresponding experimental data.

By assuming that the most probable intrados profile of the dome meridians corresponds to an upper parabola and a lower circle arc, the Authors demonstrate in Section 6 that the geometrical knowledge to design and build the dome was adequate and well known at the time the dome was built. Finally, in Section 7, a preliminary structural analysis of the dome will be performed by means of the membrane theory.

\section{THE PRIMACY OF THE DOME OF DIANA}

The architectural choice of covering a spacious circular hall with a monumental dome in opus caementicium was first made in Baiae - the pusilla Roma - for the construction of the temple of Mercury [3]. The domed circular halis of Baiae date from the late Republican to the late Severian period; the the capital. On the contrary, i first practical and architectural application at the previous investigations, such as those propos Rakob [3]. The temple of Diana ( $3^{\text {rd }}$ century AD) is the largest in Batae and its dome, for the most part still extant, is the largest in antiquity after the Pantheon; the diameter of the dome is

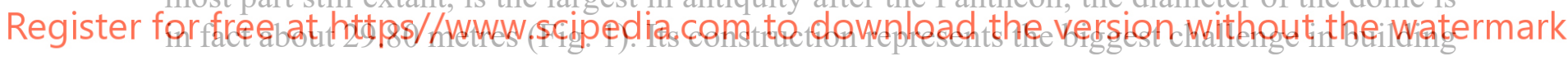
a dome in opus caementicium in Baiae: the largest rise, largest span, largest windows, and thinnest thickness of the dome. Small openings are interposed between the large, high span windows, which are surmounted by double ring splayed arches (Fig. 1).

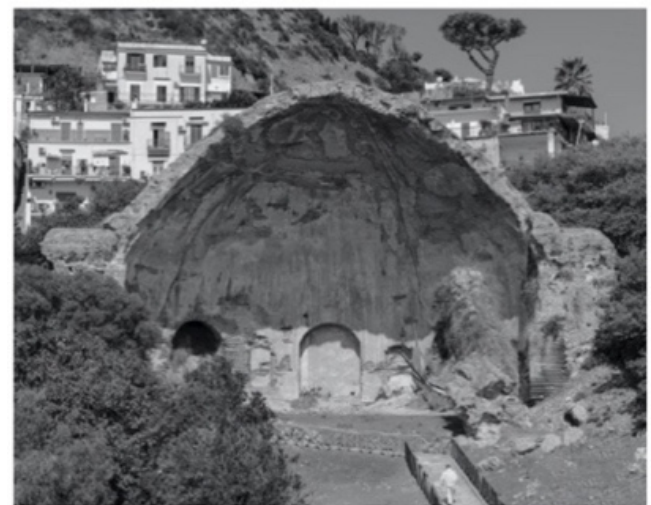

(a)

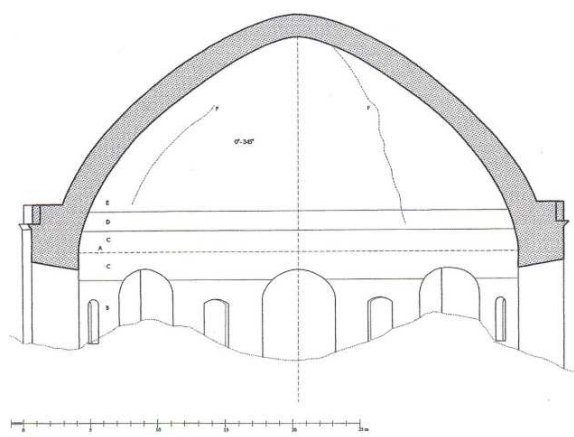

(b)

Figure 1: The temple of Diana. The remaining part (a); Rakob's vertical section (b) [3]. 
The plan of the internal hall is circular, whereas externally it is octagonal. The tambour surrounding the dome springing is very thick, as it is the only external strengthening device in the lower part of the dome. Half of the structure has collapsed; although the causes are not completely understood, this may be due to a combination of local bradyseism and earthquakes.

\section{THE RELATIONSHIP BETWEEN OCCIDENT AND ORIENT}

Because of the special techniques used in building it, the temple of Diana has been attributed to the Emperor Severus Alexander (222-235) by De Angelis d'Ossat [2], who quotes from the detailed work Vita Severi Alexandri by Aelius Lampridius: "Et in Baiano palatium cum stagno fecit, quod Mammeae nomine hodieque censetur. Fecit et alia in Baiano opera magnifica in honorem adfinium suorum et stagna stupenda admisso mari", (24, 9-10). ("And in the Baiae district he created a palace with a lake, which, named after Mamaea [his mother] is still in the records today. He also did magnificent works in Baiae, in honour of his family, and formed amazing artificial lagoons by allowing water to flow in from the sea" [translation by the Authors]

Severus Alexander (208-235 AD) was only 13 years old when he ascended to the throne: he died after about 13 years as Emperor. The leadership then passed to the women of his family, who were of Syrian origin: his grandmother Iulia Maesa and his mother Iulia Avita Mamaea. Severus was remembered as a good and gentle emperor, but he was probably not capable of dealing with the military problems that faced him. The most important event in his life was the military campaign against Ardashir-the founder of the Sassanid dysasty - who started an
offensive to win the Syrian lands from the Romans. The sequence of enents forced Severus
Alexander to leave Rome in 231 and to spend a long time - at least until 233 - in the Orient,
where his mother Iulia Mamala had joined him.
Based on the observations made by De Angelis d'Ossat [2] and the events charactorising
Severus Alexander's life, the Authors will try to demonstrate that the dome of Diana could be the opus magnificum, the Severi family's Heroon in Baiae, in the form of an Îwân.

for free at https//www.scipedia.com to download the version without the watermark

\subsection{Sassanid architecture: the Palace of Ardashir and the Temple of Diana}

During the Sassanid Empire, the most essential innovation in architecture occurred with the construction of domes, which were often erected over palace reception halls (Îwân), such as the domes over the palace of Sarvestan and Ardashir (Fig. 2) in Firuzabad. These domes provide the first known examples of the use of squinches, a technique that had an enduring effect on the development of the dome in Islamic architecture [5,6]. The palace of Ardashir ( $3^{\text {rd }}$ century AD) is the most famous and imposing domical monument of the Sassanid era, which extended from 224 to 651 . The building consists of three oval domes, with a span of $13.30 \mathrm{~m}$., resting on squinches that are used as transition parts between the horizontal polygonal section and the upper circular calotte. By analysing the organization of the various architectonic elements in the palace of Ardashir, some similarities with the organisation of space in the temple of Diana can be ascertained (see Fig. 1). Bearing in mind that the lower part of the temple of Diana collapsed due to bradyseism, it is possible to observe in both structures that small recesses intersperse the high, large span windows, which are surmounted by splayed arches. The domes of both structures seem to spring just above the arches, resting on squinches located in between two adjacent arches; the domes are immersed in the tambour (see Fig. 1, a), whereas only the 
upper cap (characterised by a small oculus in the case of the domes on the palace of Ardashir), is self-supporting with constant thickness.

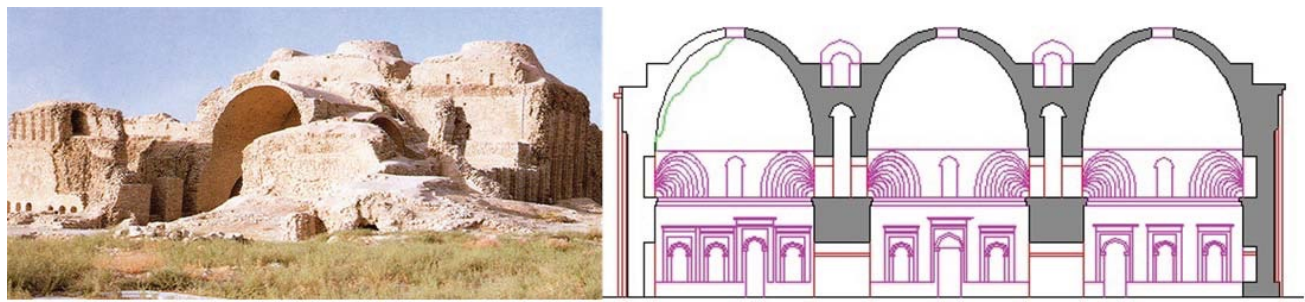

Figure 2: The palace of Sarvestan and Ardashir. Sassanid period. Firuzabad [5].

The dome's profile in both structures can be defined as gibbous. Balneum Gimburusu is in fact the term used by Pietro da Eboli (Fig. 3, left) as nickname for the temple of Diana [7]. Moreover, the oriental inspiration of the profile of the dome of Diana is proved by the Ctesiphon vault (Fig. 3, right), built in the palace of the Persian King Kosrow (591-628). The entrance hall to the palace - an Îân with a span of 26 metres and a rise of 31 metres - is one of the most emblematic examples of parabolic barrel vaults, a sign of the faraway beginnings of vaulted roofs in the Sassanid era, built according to the ancient Mesopotamian technique using bricks without centring.
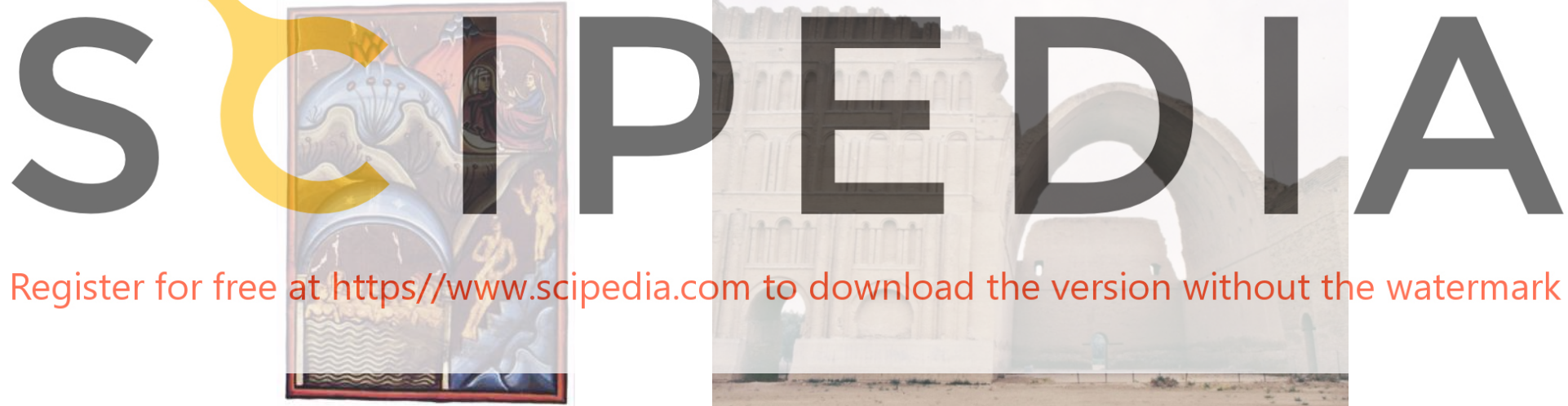

Register for free at https//www.scipedia.com to download the version without the watermark

Figure 3: Balneum Gimburusu, Biblioteca Angelica, Roma, ms. 1474, end of $13^{\text {th }}$ century, fol. 18 (left), (from Sinopoli et al. 2018); Îwân in Tâq-Kisrâ in Ctesiphon, Iraq: the vault of the Kosrow palace (right).

\section{THE DEBATED QUESTION OF THE DOME PROFILE}

With reference to the dome of Diana in Baiae, De Angelis d'Ossat affirms: "We do not know if the dome's profile - which has never been surveyed - corresponds to either one or more curves (catenary, parabola, circle's arcs). Nevertheless, the typical curve trend we have defined as ovoid, can usually be observed in the vaults of all the ancient Orient, starting with the rare significant Egyptian examples of barrel vaults" [2].

\subsection{Rakob's photogrammetric survey}

More recently, Rakob [3] tried to solve the question of the profile of the dome of Diana through a photogrammetric analysis. He thus proposed a polycentric profile composed of four 
circle arcs, characterized by two different radii and aligned centres, in order to guarantee tangency continuity along the meridians at the parallel connection. Rakob stated that the dome is characterized by span and rise equal to 100 and 50 Roman feet, respectively.

It is the Authors' opinion that, by proposing the polycentric profile, Rakob followed the analyses performed by Choisy [8], who, observing the form of many Egyptian barrel vaults, proposed an oval form composed of circular arcs with aligned centres. As a matter of fact, the oval form appeared in Europe in Roman times for the design of amphitheatres, whereas it seems that the Romans did not build oval domes characterised by a polycentric design. Moreover, it is the Authors' opinion that ascertaining the geometric profile of a dome is not only a matter of measuring, but also of historical geometric knowledge, construction tradition and problems posed in practical building by the use of a given profile $[9,10]$. These are the reasons that motivated the start of a research project in 2017, aimed at solving the controversial question of the dome profile [1].

\subsection{Recent survey of the dome of Diana and preliminary interpretations}

In accordance with the research project, the architectonic survey of the intrados of the dome of Diana was performed by Valenti and Romor [1] using two instrumental technologies: 3-D laser scanning and digital photogrammetry. The detailed analysis of the critical approach pursued during the measuring process, together with the preliminary interpretations of the results obtained, have been reported in [1].

\section{In synthesis, the contral symmetry of the d}

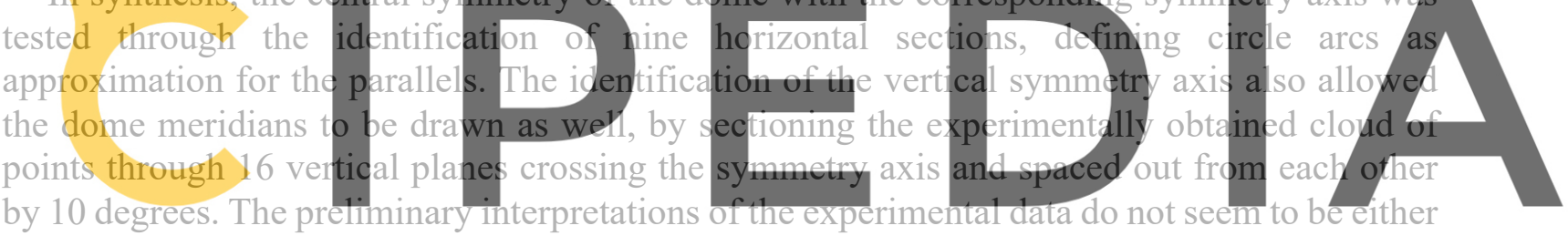
conclusive or definitive, although the polycentric profile proposed by Rakob in [3] has been

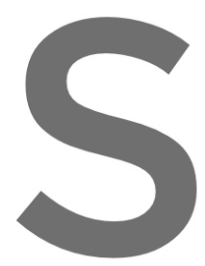

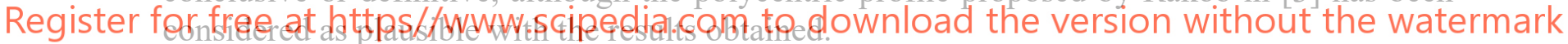

It has indeed been assumed (presuming that Rakob made the same assumption) that the springing of the dome is located just over the extrados key of the double splayed arches (see Fig. 1, b), where a horizontal string of large bricks seems to outline the plane height reached. Consequently, the rise of the dome thus identified by Valenti and Romor was found to be only 47.70 Roman feet rather than 50. Neither they nor Rakob took the experimental data of the meridian points located under the assumed springing into consideration.

Moreover, the radii of the circle arcs of the polycentric profile turned out on the whole to be significantly lower than those proposed by Rakob.

\section{SEARCHING FOR THE DOME PROFILE}

To begin their investigation the Authors made use of the numerical file kindly provided by Valenti and Romor [1], which includes all the geometrical data of the 16 meridians surveyed. By performing analytical elaborations based on these data, the Authors have tried to solve the question of the meridians' profile. On her first on-site inspection in Baiae in 2016, the first Author certainly had the impression that the extrados profile of the dome of Diana over the tambour was parabolic; this impression needed to be analysed. 


\subsection{Theoretical investigation into possible profiles}

Before analysing the experimental numerical data, it was necessary to investigate if, assuming Rakob's theoretical features of the dome design - namely, the dome's span and rise corresponding to 100 and 50 R.ft., respectively -, it was possible to identify a polycentric profile made up of a lower circle arc, with its centre at the same height as the dome springing, and an upper curve - either a circle or a parabolic arc - matched in tangency continuity conditions.

For the profile composed of a lower circle arc and an upper parabola, the tangency continuity requirement for the connecting point identified infinite solutions depending only on the lower circle arc radius. By considering a radius equal to 37 Roman feet for the lower circle arc, as proposed by Rakob, both the parabola curvature and the matching point $C$ have been identified; the curvature is equal to -0.0153 , while the connection occurs for $x_{C}=42.2885$ Roman feet and $y_{C}=22.6093$ R.ft., respectively, as shown in Fig. $4 a$.


Figure 4: Theoretical dome profiles, composed of a lower circle arc, with radius $r=37$ Roman feet: theoretical Register for free at upper parabolic arc (a); upper Rakob's circle arc with rqdius $r_{u}=80$ Roman feet (b).

The search for Rakob's theoretical polycentric curve has been simpler. If the radii of the two circle arcs are assumed equal to $r_{l}=37$ and $r_{u}=80$ Roman feet, respectively, as Rakob proposed, in this case (Fig. $4, b$ ), the coordinates of the upper circle centre are $x_{A}=-20.1150$ R.ft. and $y_{A}$ $=-27.4299$ R.ft., while the matching point lies at the height of $y_{C}=23.6024$ R.ft.. Obviously, a slight modification of the value of either radius is sufficient to obtain different values for both the centre coordinates of the other circle and the height of the connecting point. In conclusion, if the radii of the two circle arcs are unknown and the dome span and rise are given, $\infty^{2}$ solutions corresponding to Rakob's polycentric profile exist; moreover, if the dome rise is changed a further indeterminacy is added to the problem.

\subsection{Comparison between theoretical and experimental data}

Identification of the value of the lower arc radius - which better approximates the experimental data distribution - has been obtained from the comparison between the experimental data with the results of the theoretical analysis of a profile made of a lower circle and an upper parabola. Moreover, it has been possible to demonstrate that the dome's springing is at the zero value of the $y$ coordinate, where the tangent's slope to the profile is $90^{\circ}$. 
The dome starts with eight squinches located in between two adjacent arches; the squinches end just above the extrados of the double splayed arches, where the intrados parallel of the dome finally becomes a whole circle. This relevant result confirms the oriental inspiration of the temple of Diana in the use of squinches to connect the springing to the circular contour of the upper calotte.

The procedure adopted to compare theoretical results and surveyed data - a reliable approximation of the standard statistical regression - considered the analytical expression of the assumed profile and the known experimental coordinates; both $y$ coordinates corresponding to the same experimental $x$ coordinate were then evaluated, in order to compare theoretical and experimental $y$ and minimise the mean absolute deviation of the corresponding distributions.

Fig. $5 a$ shows the distribution of the points encompassing the sixteen theoretical meridian profiles corresponding to the upper parabola and lower circle arc, in comparison with the experimental data; the value of the lower circle radius is equal to 37 Roman feet, as already found by Rakob.
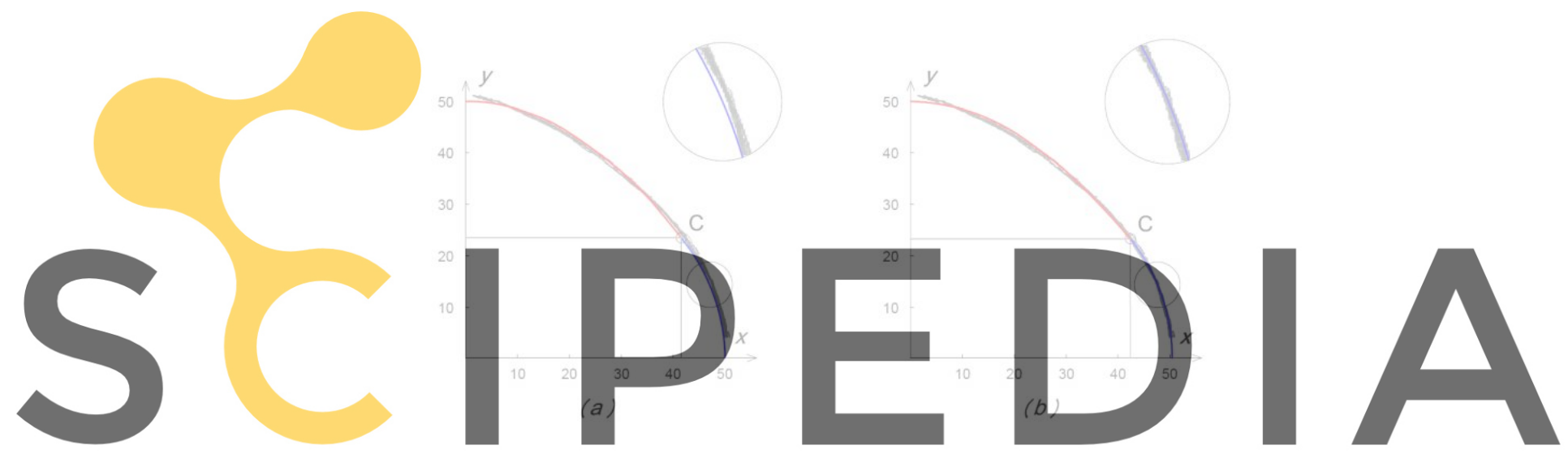

Figure 5: Theoretical parabolic-circle arc profile and experimental data (a); best-fit parabolic-circle arc

Register for free at https//www.scipedtailcametouchowmbaabthe version without the watermark

Figure $5 a$ suggests that the theoretical parabola approximates the experimental data; however, it shows a mean deviation of the lower circle arc, as if the built dome was characterized by a span larger than 100 Roman feet. By slightly modifying the centre coordinate $x$ of the lower circle, it has been possible to obtain the best-fit dome profile shown in Fig. $5 b$; the centre coordinate $x$ of the lower arc is $x=13.41$ (rather than 13), corresponding to a dome span of 100.82 R.ft.. Obviously, the best-fit matching point coordinates are changed: they become $x=42.3354$ and $y=23.0058$, respectively.

An investigation similar to that discussed so far was also performed for Rakob's polycentric curve, made of two circle arcs of radii equal to 37 and 80 Roman feet, respectively. The comparison with the experimental data is shown in Fig. $6 a$; the assumed rise and span of the dome are still 50 and 100 Roman feet. As can be observed, in addition to the deviation of the lower circle arc, probably due to an actual span larger than 100 Roman feet, as in Fig. $5 a$, agreement between the upper circle arc and experimental data is lacking.

When looking for a best-fit polycentric profile the parameters on which the problem depends must be modified. For the lower circle arc, it is sufficient to increase the $x$ coordinate of its centre; for the upper circle arc, on the contrary, the indeterminacy is doubled, since its profile 
depends on both the dome rise and the upper circle radius. Assuming the experimental dome rise to be correct, it is clear that the possible polycentric profile admits infinite solutions, depending on the radius and the corresponding centre of the upper circle. Moreover, by varying both the rise and the radius among infinite possibilities, a very good approximation can be obtained; the comparison between experimental data and best-fit polycentric profile obtained is shown in Fig. $6 b$. The theoretical rise of the dome is, however, equal to 51.41, whereas the upper radius corresponds to 79.70 feet and the connection point is at a height of about 22 feet.
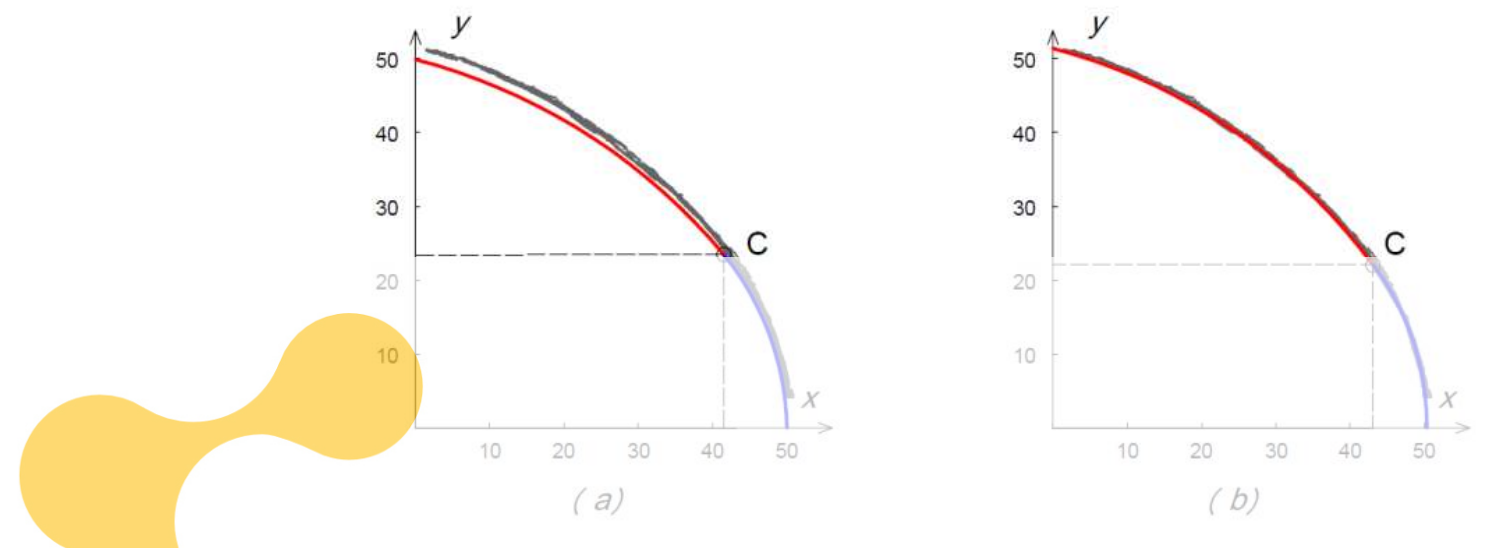

Figure 6: Theoretical Rakob's circle arcs and experimental data (a); best-fit polycentric circle arcs and


Roman feet, in agreement with a consistent theoretical design, by obtaining a fake agreement

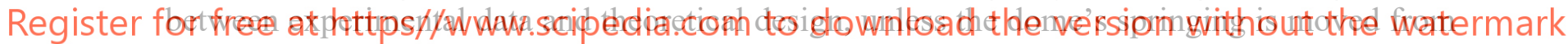
$\mathrm{y}=0$ R.ft. to $\mathrm{y}=1.5$ R.ft.. To confirm this, the absolute $\Delta y$ deviations distributions of the two theoretical upper profiles (circular and parabolic, respectively), corresponding to a dome rise equal to 50 Roman feet, and evaluated with respect to the experimental data, are shown in Fig. 7; Rakob's deviations distribution is double that of the parabolic profile.

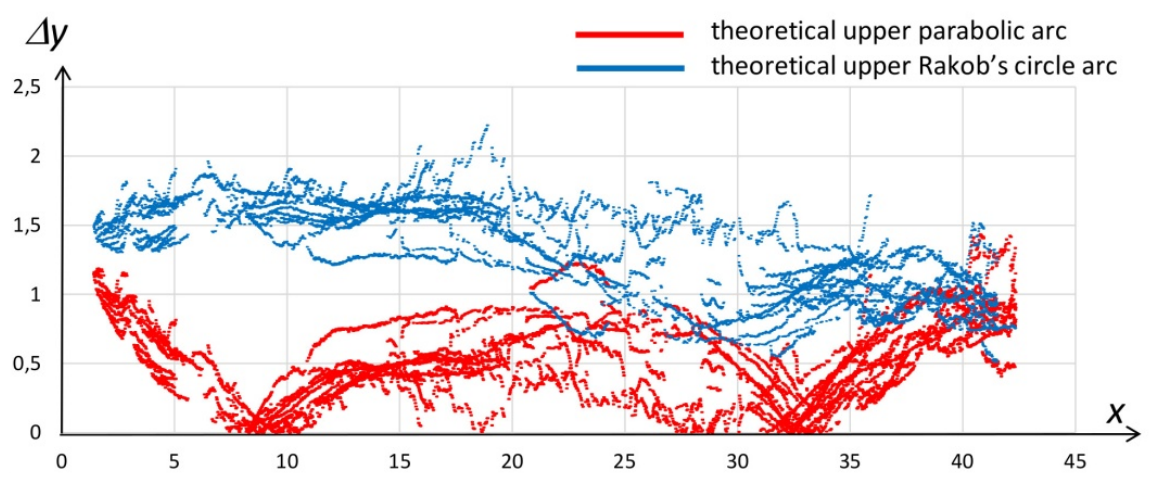

Figure 7. Absolute $\Delta y$ deviations distributions between theoretical upper profiles and experimental data. Both distributions correspond to a dome rise and span equal to 50 and 100 Roman feet, respectively. 


\section{FROM THEORY TO PRACTICE}

To support the Authors' opinion that the theoretical profile of the dome of Diana is composed of a lower circle arc and an upper parabola matched at the height of about 23 Roman feet, let us analyse the geometric knowledge assumed to have been acquired by the time of the dome's construction. The period in which the body of Greek geometric rules was formed extends from the third century $\mathrm{BC}$ to $550 \mathrm{AD}$, that is, from the Hellenistic civilization of the Mediterranean basin and throughout the Roman dominion, until the time of the Byzantine hegemony. Euclid (about 300 BC), Archimedes (287-212 BC) and Apollonius (262-190 BC) form the triad of the greatest Greek geometers.

\subsection{Apollonius of Perga and the Conics}

Apollonius's fame is due to his Conics, a fundamental work that is partly a collection of instruments deduced from preceding scientists (including Euclid), and partly an original treatise containing very profound results. Apollonius uses as reference the stereometric origin of conics only to obtain the fundamental properties of each one - these are plane properties constituting the basis for further theoretical developments. The most important of Apollonius's theorems concerning the properties of the parabola, useful for the purposes of this paper are contained in book I of his Conics [11].

His Proposition I.II can be detailed as follows: Let $Q V$ be any ordinate relative to the symmetry axis $P M$ (Fig. 8). If a line is drawn, crossing $P$ and perpendicular to $P M$, then: $Q V^{2}$ $=P L \times P V$, where $P L$ is a defined constant segment named as "right side of the parabola. This proposition and the segment $P L$ are precisely the parabola "symptom" and the "right side"
respectively, which allow the construetion of a parabola starting from a circle, the diameter of which represents the "right sic" In Propositions I. parabola, in this way: consider a point $T$ (Fig. 9), along the symmetry axis of a parabola and

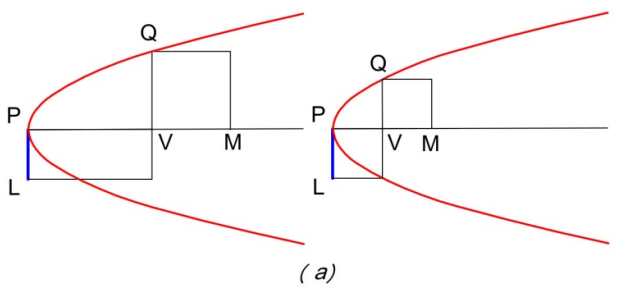

Figure 8: The parabola “symptom”.



Figure 9: Drawing the tangent to a parabola.

These theorems are fundamental for defining the features of a dome design, the profile of which corresponds to an upper parabola and a lower circle arc, once the dome span and rise have been defined. In fact, having fixed only the height $S V$ of the connection between lower circle arc and upper parabola, it is possible to identify the unique right-angled triangle $T Q C$, 
with its right-angle at point $Q$ (Fig. 9), which intercepts the lower circle centre $C$ at the springing height, guaranteeing the tangency continuity condition of the two curves at point $Q$.

\section{STRUCTURAL ANALYSIS OF THE DOME OF DIANA}

The static regime of an axio-symmetrical dome subject to its own weight depends on the profile of the meridians. The search for its best shape is, in fact, the extension in 3-D of that funicular principle, according to which the funicular curve of a load distribution is the best shape for plane arches and ropes of negligible thickness, by guaranteeing equilibrium in terms of pure compressive/tensile stresses.

In fact, the spatial organization of an axio-symmetrical dome is always able to resolve its static functions in terms of compressive and tensile stresses, since the hoop forces provide the missing action deriving from the deviation of the meridian profile from the funicular curve. This peculiarity allows a thin dome, built with material resistant to both tension and compression, to be characterized by membrane behaviour and configures it as a thin form resistant structure. For a hemispherical dome, compression is guaranteed along the meridians: it grows from the crown to the springing. Along the parallels, on the other hand, the stress state is characterized by a reversal of the sign at a colatitude of $51.82^{\circ}$ : compressive stresses decrease from the crown to the critical parallel, while a state of increasing tensile stresses manifests itself as far as the springing.

Depending on the shape of the dome profile, however, the colatitude of the critical parallel

could tend to approach the spinging: a cap-like regime - characterized by compression along
both meridians and parallels - could there fore act on most of the dome. Is this the reason why
the dome of Diana is characterized by a parabolic upper profile (Fig. 1)? In the next Section
some preliminary results obtained using membrane theory are presented.
7.1 Membrane theory of shells for identifying the theoretical stress state

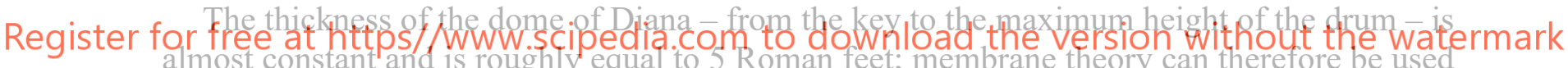
to perform its structural analysis. The dome under examination is subjected to axial symmetrical loading, represented by its self-weight; it is characterised by intrados height and span equal to 50 and 100 feet, respectively, while the intrados profile corresponds to the theoretical upper parabolic and lower circular curves identified in Section 5 (Fig. 5a).

By adopting the same notation proposed in [12], Figure 10 shows dimensionless meridian and hoop forces $s_{1}(x)$ and $s_{2}(x)$, obtained by dividing the forces $S_{1}$ and $S_{2}$ by span, thickness and specific weight. It can be seen that meridian forces are compressive along the whole dome (Fig. 10b), whereas hoop forces are compressive only in the upper parabolic segment (Fig. 10c); tensile hoop forces, in fact, arise below the connection joint (Fig. 10a).

This relevant result can thus justify why the height of the drum is roughly equal to that of the connection point between lower circle and upper parabola: thus the self-supporting portion of the dome is the only part that corresponds to the upper parabolic segment, while the lower part is completely immersed in the drum, which acts as an extended buttress. In this case, the lower arc-shaped intrados profile simply has a merely aesthetic role, being only a geometric connection in tangency continuity conditions rising with the parabola and descending with the vertical drum. 
A further controversial question tackled by the Authors concerns the possibility of building the dome of Diana in opus caementicium without the need of global supporting centring. Therefore dome-building processes, and in particular domes corresponding to different steps of construction, have been considered. These domes (Fig. 11) are characterised by an increasing rise, so that the diameter of the oculus - measured at the intrados - varies with the dome height from 100 R.ft. (first construction stage) to zero (last construction stage) in correspondence to the achieved rise of 50 Roman feet.

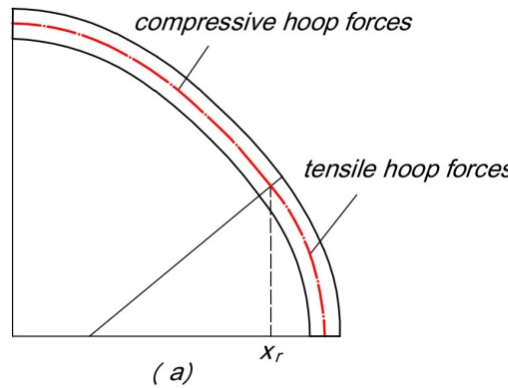

(a)

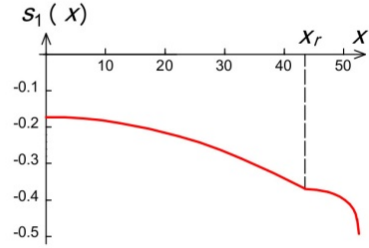

(b)

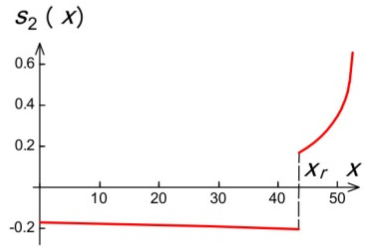

(c)

Figure 10: Profile made of an upper parabola and lower circle arc. $s_{1}(x)$ and $s_{2}(x)$, as function of abscissa $x$.

Making use of membrane theory, it was demonstrated that, whereas meridian forces are always compressive irrespective of the dome rise achieved, hoop forces are always characterised by a change of sign. The height $y_{\zeta}$ at which such a change of sign occurs is always lower than the rise reached $y_{\omega}$ (Fig. 11); during the simulated construction process, therefore, hoop forces are compressive in the upper part of the dome and tensile in the lower part.

The position of the change of sign varies as long as the building process in elevation, until it asymptotically converges to a stable value. It is worthwhile to observe that the height of the rise over which hoop forces are always compressive corresponds exactly to the connection between the upper parabolic and lower circle-arc intrados profile. In this case, the asymptotic height corresponding to the change of sign is identified by the value $y_{\zeta}=24.4$ Roman feet at the axis line; the corresponding oculus height $y_{\omega}$ is greater than $40.8 \mathrm{R}$.ft.

Thus, De Angelis d'Ossat's opinion [2] that the dome was built from the intrados side without global centring, as a standard masonry wall, is now decisively confirmed by the above.
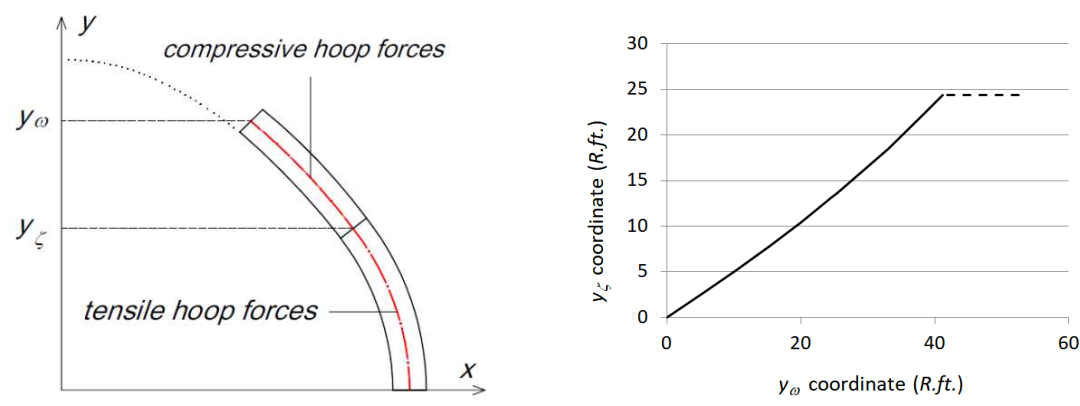

Figure 11: Varying height $y_{\zeta}$ at which hoop forces change sign (continuous line) and asymptotic behaviour (dotted line), as function of the oculus height $y_{\omega}$ reached. 


\section{CONCLUSIONS}

The temple of Diana ( $3^{\text {rd }}$ century AD) is the largest in Baiae and its dome, for the most part still extant, is the largest in antiquity after the Pantheon; the diameter of the dome is in fact about 29.80 metres. Its construction represents the biggest challenge in building a dome in opus caementicium: the largest rise, largest span, largest windows, and thinnest thickness.

De Angelis d'Ossat first recognized in the dome's profile an ovoid shape by him ascribed to an oriental tradition, that the Authors recognised as belonging to the Sassanid architecture. Moreover, since ascertaining the geometric profile of a dome is not only a matter of measuring, but also of historical context, geometric knowledge and traditions in construction, the Authors first performed a theoretical investigation on possible geometric profiles, having assumed the fundamental features of the dome's span and rise [3]. Then, the most probable dome's design has been identified by comparison with the experimental data of a recent architectonic survey [1]: the upper dome's meridian profile is a unique curve - to be precise, a parabola, the best approximation of a catenary -, which immerses itself in the tambour. Finally, the geometric knowledge presumed to be known at the time of dome's construction has been verified, and a preliminary structural analysis of a dome has been performed by using membrane theory.

It is worthwhile to outline that the Romans' primacy in dome construction was the result of their awareness (based on intuitive and experimentally verified knowledge) of the static flow generated in a dome depending on its geometric profile. In any case, the building techniques adopted were based not only on empiricism, but also on theoretical knowledge of a substantially geometric nature. In fact, from an early start in Greek cultural history, up to the $17^{\text {th }}$ century, Mechanics was to develop as a Science of Weights governed by Geometry.

\section{REFERENCES}

[1] Sinopoli, A., Valenti, G.M., Bruno, M., Conti, C., Romor J. and Martines, G. Primato romano delle volte: Il tempio di Diana a Baia, In: S. D'Agostino et al. (Eds.), History of Engineering, Cuzzolin, Napoli, (2018), Vol I, pp. 57-72.

[2] De Angelis d'Ossat, G. L'architettura delle Terme di Baia, In: I Campi Flegrei nell'archeologia e nella storia, Atti dei Convegni Lincei (1977) 33: 227-274.

[3] Rakob, F. Römische Kuppelbauten in Baiae, In: Mitteilungen des Deutschen Archäologischen Instituts, Römische Abteilung, (1988) 95: 257-301.

[4] Maiuri, A. I Campi Flegrei, Roma (1958).

[5] Grabar, O. Islamic art and beyond, Variorum Press, United Kingdom (2006).

[6] Ashkan, M., and Ahmad Y. Persian Domes: History, morphology and typologies. ArchnetIJAR, International Journal of Architectural Research (2009) 3(3): 98-115.

[7] Maddalo, S. Petrus de Ebulo, Nomina et Virtutes Balneorum seu De Balneis Puteolonorum et Baiarum. Codice Angelico 1474 (1998), Istituto Poligrafico dello Stato, Roma.

[8] Choisy, A. L'art de bâtir chez les Égyptiens, E. Rouveyre, Paris, (1904).

[9] Huerta, S. Oval domes: History, Geometry and Mechanics, Nexus Network Journal (2007) 9(2): 211-248.

[10] Migliari, R. Ellissi e ovali: epilogo di un conflitto, Palladio (1995) 8(16): 93-102.

[11] Apollonius, Apollonius of Perga Conics Books I-III, Translated by R. Catesby Taliaferro, Santa Fe, Green Lion Press (1998).

[12]Belluzzi, O. Scienza delle costruzioni, Zanichelli, Vol. III, (1982), pp. 245-270. 